\title{
Study on the Correlation Analysis of Energy Consumption in Economic Industries and Evaluation of Carbon Emission Decoupling in Beijing-Tianjin-Hebei Region
}

\author{
Dan $\mathrm{Wu}^{1, *}$ Chenhui $\mathrm{Ji}^{2}$ \\ ${ }^{1}$ School of Economics and Management, North China University of Technology, Beijing 100144 \\ ${ }^{2}$ Department of Mathematics, Imperial College London, London SW7 2AZ, UK \\ *Corresponding author. Email: wu_daniel@163.com
}

\begin{abstract}
A deep exploration of the correlation analysis of energy consumption in economic industries and evaluation of carbon emission decoupling in Beijing-Tianjin-Hebei region can provide important reference for its government departments in decision-making to accelerate the formulation and improvement of energy consumption control policies and systems. In this paper, by use of the grey incidence analysis, the correlation analysis model of energy consumption and economic growth in the economic industries of Beijing-Tianjin-Hebei region was built to analyse the correlation characteristics of industrial energy consumption and economic growth in BeijingTianjin-Hebei region. Meanwhile, based on the indexes of economic output value and carbon emission efficiency in Beijing-Tianjin-Hebei region, a carbon emission increment model was set up to measure the contributions of carbon emission structure increment and efficiency increment in the region. And the Tapio elastic coefficient method was adopted to identify the decoupling trend of carbon emissions in Beijing-TianjinHebei region. Finally, the corresponding countermeasures and suggestions were put forward to provide support for the government departments of Beijing-Tianjin-Hebei region to accelerate the formulation and improvement of policies and measures for decoupling economic growth from energy consumption and carbon emissions in the economic industries of this region.
\end{abstract}

Keywords: Beijing-Tianjin-Hebei region, Industry, Energy consumption, Carbon emissions, Decoupling, Evaluation.

\section{INTRODUCTION}

Beijing-Tianjin-Hebei region is one of the three most dynamic economic growth poles in China. In April 2015, the Political Bureau of the CPC Central Committee adopted the Outline of the Coordinated Development Plan for Beijing-Tianjin-Hebei region. This lifted the coordinated development of

*Funds: General Project of Beijing Natural Science Foundation "Research on the Bidirectional Optimal Adaptation of Water Resources and Industrial Structure Under the Coordinated Development of Beijing-Tianjin-Hebei Region" (No. 9202005); Yuyou Talent Project of North China University of Technology "Research on the Evaluation System of BeijingTianjin-Hebei Region's Resource Energy Consumption Management Performance and Its Cooperative Governance Capability from the Perspective of Technological Innovation" (No. XN020035). the region to a major national strategy, stressed the need to enhance the resource and energy guarantee capacity of Beijing-Tianjin-Hebei region, and made industrial upgrading and transfer and ecological and environmental protection the key fields for the coordinated development of the region. From 1996 to 2016, the energy consumption in BeijingTianjin-Hebei region showed a continuous growth trend. Among the three, Beijing increased its energy consumption from 37.345 million tons to 69.617 million tons, which nearly doubled; Tianjin from 23.741 million tons to 80.414 million tons, up by more than 2 times; and the increase of energy consumption in Hebei was about 6.5 times that of Beijing and 3.7 times that of Tianjin. Facing the strategic needs of industrial transformation and 
upgrading and ecological environment protection in the process of Beijing-Tianjin-Hebei coordinated development, a research on the correlation analysis of energy consumption in economic industries and evaluation of carbon emission decoupling in Beijing-Tianjin-Hebei Region is of great practical significance to accelerate industrial transformation and upgrading, control and reduce energy consumption and carbon emissions, and promote high-quality economic development in the region.

\section{LITERATURE REVIEW}

In the 1960s, the scholar Carter [1] first discussed the decoupling problem between economic development and environmental pressure. German scholars Weizsacker and Schmidt-Bleek [2-3] put forward the important conclusion of "realizing the decoupling of resource and energy consumption and economic growth and promoting sustainable development" at the end of the 20th century. In the early 2000s, the OECD defined decoupling as breaking the link between "environmental harm" and "economic wealth" [4]. Since the 21 st century, the decoupling between energy consumption and economic growth has attracted extensive attention from scholars at home and abroad. Scholars mainly focus on the construction pattern of decoupling indicators and the division of decoupling states. For example, OECD and Tapio proposed the OECD decoupling indicator model [4] and Tapio decoupling indicator model [5] respectively. Vehmas and Tapio et al. [57] summarized 3 types of decoupling and 8 types of decoupling states. At the meantime, scholars combined with the national conditions of each country to conduct quantitative research on the relationship between energy consumption and economic growth decoupling. For example, Kraft [8], Paul [9], Climentd [10], Voet [11-12] and others have constructed energy consumption decoupling indexes, which respectively verified the long-term decoupling relationship between energy consumption and economic growth in the United States, India, Spain and EU member states.

Since 2010, China has become the world's largest energy consumer and carbon emitter. The pressure of energy conservation and emission reduction has become more prominent. How to decouple energy consumption carbon emissions from economic growth on the premise of ensuring high-quality economic development in China has become a research hotspot of the government authorities and domestic scholars. With the application of decoupling index method, complete decomposition model and other models and methods, scholars have conducted practical exploration on the decoupling of energy consumption carbon emissions and economic growth from the perspectives of industrialization, urbanization and carbon emissions, focusing on two aspects: different spatial scales [13-23] and different industrial development [24-27]. These findings provide an important reference for clarifying the decoupling trend and driving factors between energy consumption carbon emissions and economic growth at the national, provincial and industrial levels. In addition, Cheng Haisen et al. [28-33] focused on a quantitative study on the decoupling relationship between energy consumption, carbon emissions and economic growth in the process of Beijing-Tianjin-Hebei coordinated development.

In this paper, the correlation analysis of economic and industrial energy consumption and the evaluation of carbon emission decoupling in Beijing-Tianjin-Hebei region are discussed. On the one hand, the grey incidence analysis method was adopted to construct the correlation analysis model of industrial energy consumption and economic growth in Beijing-Tianjin-Hebei region, and to analyse the correlation characteristics of industrial energy consumption and economic growth in the region. On the other hand, according to the economic output value index and carbon emission efficiency index of Beijing-Tianjin-Hebei region, the carbon emission increment model of BeijingTianjin-Hebei region was built to measure the contribution of the carbon emission structure increment and efficiency increment in BeijingTianjin-Hebei region. The Tapio elastic coefficient method was also used to identify the decoupling trend of carbon emissions in Beijing-Tianjin-Hebei region. Finally, corresponding countermeasures and suggestions were put forward to support the government departments of Beijing-Tianjin-Hebei region in accelerating the formulation and improvement of policies and measures for decoupling economic growth and energy consumption and carbon emissions in the economic industries of this region. 


\section{CORRELATION ANALYSIS MODEL OF ENERGY CONSUMPTION IN ECONOMIC INDUSTRIES IN BEIJING- TIANJIN-HEBEI REGION}

The correlation characteristic analysis of economic industrial energy consumption in BeijingTianjin-Hebei region is to measure the correlation degree between the energy consumption and output value of economic industrial in different periods from the perspective of change quantity and change rate, so as to determine the dependence degree of the output value growth of economic industries in Beijing-Tianjin-Hebei region on its energy consumption. Grey incidence analysis is a measure of the similarity and magnitude of the development trends of two sequence curves. In other words, it is the measure of the absolute correlation degree, relative correlation degree and comprehensive correlation degree of the two sequence curves according to the absolute value of the area between the two sequence curves. ${ }^{[34]}$ Therefore, the grey incidence analysis method was adopted to measure the correlation degree between the economic industrial energy consumption in Beijing, Tianjin and Hebei and the economic industrial output value of Beijing, Tianjin and Hebei respectively, taking the industrial output value of Beijing, Tianjin and Hebei as the reference sequence. The comprehensive correlative degree of energy consumption of the $j$ industry and the output value of the $j$ industry in the $i$ area of Beijing-TianjinHebei region can be presented by the formula $\gamma_{0 i j}$ :

$$
\begin{gathered}
\gamma_{0 i j}=\theta \alpha_{0 i j}+(1-\theta) \beta_{0 i j} \\
\alpha_{0 i j}=\frac{1+\left|\mathrm{s}_{0 j}\right|+\left|\mathrm{s}_{i j}\right|}{1+\left|\mathrm{s}_{0 j}\right|+\left|\mathrm{s}_{i j}\right|+\left|\mathrm{s}_{i j}-\mathrm{s}_{0 j}\right|} \\
\beta_{0 i j}=\frac{1+\left|\mathrm{s}_{0 j}^{\prime}\right|+\left|\mathrm{s}_{i j}^{\prime}\right|}{1+\left|\mathrm{s}_{0 j}^{\prime}\right|+\left|\mathrm{s}_{i j}^{\prime}\right|+\left|\mathrm{s}_{0 j}^{\prime}-\mathrm{s}_{i j}^{\prime}\right|}
\end{gathered}
$$

In formula (1), $\alpha_{0 i j}$ and $\beta_{0 i j}$ represent the absolute correlation and relative correlation between the energy consumption in the $j$ industry and the $j$ industry in the $i$ area of Beijing-TianjinHebei region, respectively ( $i=1,2,3$ represent Beijing, Tianjin and Hebei, separately; $j=1,2,3$ represent the primary, secondary and tertiary industries respectively); $\theta$ is the resolution ratio, and $\theta \in(0,1)$, is usually at 0.5 .
In formula (1), $\left|s_{0 j}\right|=\left|\sum_{t=2}^{n-1} x_{0 j}^{0}(t)+\frac{1}{2} x_{0 j}^{0}(n)\right|$ represents the area enclosed by the sequence curve of industrial output value in the $j$ industry of Beijing-Tianjin-Hebei region and the horizontal axis; $\left|s_{i j}\right|=\left|\sum_{t=2}^{n-1} x_{i j}^{0}(t)+\frac{1}{2} x_{i j}^{0}(n)\right|$ represents the area enclosed by the sequence curve of energy consumption in the $j$ industry in the $i$ area of the region and the horizontal axis; $\left|s_{i j}-s_{0 j}\right|=\left|\sum_{t=2}^{n-1}\left(x_{i j}^{0}(t)-x_{0 j}^{0}(t)\right)+\frac{1}{2}\left(x_{i j}^{0}(n)-x_{0 j}^{0}(n)\right)\right|$ represents the absolute value of the area between two sequence curves of the energy consumption in the $j$ industry and the industrial output value of the $j$ industry in the $i$ area of the region. In it, $X_{0 j}^{0}(t)=\left\{\mathrm{x}_{0 j}(t)-\mathrm{x}_{0 j}(1), t=2,3 \cdots \mathrm{n}\right\}, \quad$ in which $\mathrm{x}_{0 j}(t)$ represents the industrial output value of the $j$ industry of Beijing-Tianjin-Hebei region in period $t ; x_{i j}^{0}(t)=\left\{\mathrm{x}_{i j}(t)-\mathrm{x}_{i j}(1), t=2,3 \cdots \mathrm{n}\right\}$, in which $\mathrm{x}_{i j}(t)$ represents the energy consumption of the $j$ industry of the $i$ area in the region in period $t$

In formula (1), $\left|\mathrm{s}_{0 j}^{\prime}\right|=\left|\sum_{t=2}^{n-1} x_{0 j}^{0^{\prime}}(t)+\frac{1}{2} x_{0 j}^{0^{\prime}}(n)\right|$, represents the area enclosed by the sequence curve of industrial output value in the $j$ industry of Beijing-Tianjin-Hebei region and the horizontal axis; $\left|\mathrm{s}_{i j}^{\prime}\right|=\left|\sum_{t=2}^{n-1} x_{i j}^{0^{\prime}}(t)+\frac{1}{2} x_{i j}^{0^{\prime}}(n)\right|$, represents the area enclosed by the sequence curve of energy consumption in the $j$ industry in the $i$ area of the region and the horizontal axis; $\left|\mathrm{s}_{0 j}^{\prime}-\mathrm{s}_{i j}^{\prime}\right|=\left|\sum_{t=2}^{n-1}\left(x_{i j}^{0^{\prime}}(t)-x_{0 j}^{0^{\prime}}(t)\right)+\frac{1}{2}\left(x_{i j}^{0^{\prime}}(n)-x_{0 j}^{0^{\prime}}(n)\right)\right|$, represents the absolute value of the area between two sequence curves of the energy consumption of the $j$ industry and the industrial output value of the $j$ industry in the $i$ area of the region; and $X_{0 j}^{0}(t)=\left\{\frac{\mathrm{x}_{0 j}(t)-\mathrm{x}_{0 j}(1)}{\mathrm{x}_{0 j}(1)}, t=1,2 \cdots \mathrm{n}\right\} \quad, \quad$ and $X_{i j}^{0^{\prime}}(t)=\left\{\frac{\mathrm{x}_{i j}(t)-\mathrm{x}_{i j}(1)}{\mathrm{x}_{i j}(1)}, t=1,2 \cdots \mathrm{n}\right\}$. 


\section{EVALUATION MODEL OF CARBON EMISSION DECOUPLING IN BEIJING- TIANJIN-HEBEI REGION}

\subsection{Carbon Emission Increment Model}

According to the index of economic output value and carbon emission efficiency in BeijingTianjin-Hebei region, the total amount and increment of carbon dioxide emission in the region can be determined, which can be expressed by the formula:

$$
\left\{\begin{array}{l}
E_{i}^{t}=Y_{i}^{t} \cdot E G_{i}^{t} \\
C_{i}^{t}=Y_{i}^{t} \cdot C G_{i}^{t} \\
\Delta E_{i}^{t}=E_{i}^{t}-E_{i}^{0}=Y_{i}^{t} \cdot E G_{i}^{t}-Y_{i}^{0} \cdot E G_{i}^{0} \\
\Delta C_{i}^{t}=C_{i}^{t}-C_{i}^{0}=Y_{i}^{t} \cdot C G_{i}^{t}-Y_{i}^{0} \cdot C G_{i}^{0}
\end{array}\right.
$$

In formula (2), $\Delta C_{i}^{t}$ represents the increment in carbon dioxide emissions of the $i$ area in BeijingTianjin-Hebei region in period $t \quad(i=1,2,3,4$ represent Beijing, Tianjin, Hebei and BeijingTianjin-Hebei, respectively). $C_{i}^{t}$ and $C_{i}^{0}$ separately represent the total carbon dioxide emissions of the $i$ area in Beijing-Tianjin-Hebei region in period $t$ and the base period; $Y_{i}^{t}$ represents the total economic output value of the $i$ area of BeijingTianjin-Hebei region in period $t$, and $C G_{i}^{t}$ is the carbon emission efficiency of the $i$ area of BeijingTianjin-Hebei region in period $t$, that is the carbon emissions per 10,000 yuan of GDP of the $i$ area in Beijing-Tianjin-Hebei region in period $t ; Y_{i}^{0}$ is the economic output value of the $i$ area of BeijingTianjin-Hebei region in the base period; $C G_{i}^{0}$ represents the carbon emission efficiency of the $i$ area of Beijing-Tianjin-Hebei region in base period.

According to Equation (2), carbon dioxide emissions in Beijing-Tianjin-Hebei region were affected by changes in industrial structure and carbon emission efficiency. For this reason, $\Delta E_{i}^{t}$ and $\Delta C_{i}^{t}$ were decomposed to determine the carbon emission structure increment and efficiency increment in the $i$ area of Beijing-Tianjin-Hebei region, which can be expressed as:

$$
\begin{gathered}
\Delta E_{i}^{t}=\Delta E_{i s}^{t}+\Delta E_{i e}^{t} \\
\Delta C_{i}^{t}=\Delta C_{i s}^{t}+\Delta C_{i e}^{t} \\
\left\{\begin{array}{l}
\Delta E_{i s}^{t}=E G_{i}^{0}\left(Y_{i}^{t}-Y_{i}^{0}\right)+\frac{1}{2}\left(E G_{i}^{t}-E G_{i}^{0}\right)\left(Y_{i}^{t}-Y_{i}^{0}\right) \\
\Delta E_{i e}^{t}=Y_{i}^{0}\left(E G_{i}^{t}-E G_{i}^{0}\right)+\frac{1}{2}\left(E G_{i}^{t}-E G_{i}^{0}\right)\left(Y_{i}^{t}-Y_{i}^{0}\right) \\
\Delta C_{i s}^{t}=C G_{i}^{0}\left(Y_{i}^{t}-Y_{i}^{0}\right)+\frac{1}{2}\left(C G_{i}^{t}-C G_{i}^{0}\right)\left(Y_{i}^{t}-Y_{i}^{0}\right) \\
\Delta C_{i e}^{t}=Y_{i}^{0}\left(C G_{i}^{t}-C G_{i}^{0}\right)+\frac{1}{2}\left(C G_{i}^{t}-C G_{i}^{0}\right)\left(Y_{i}^{t}-Y_{i}^{0}\right)
\end{array}\right.
\end{gathered}
$$

In Formula (3), $\Delta C_{i s}^{t}$ represents the structural increment of carbon emission in the $i$ area of Beijing-Tianjin-Hebei region during period $t$, that is the increment of carbon dioxide emission caused by the change of economic output value in the $i$ area of Beijing-Tianjin-Hebei region during period $t ; \Delta C_{i e}^{t}$ represents the carbon emission efficiency increment of the $i$ area in Beijing-Tianjin-Hebei region during period $t$, that is the increment of carbon dioxide emissions caused by the change of carbon emissions of per 10,000 yuan GDP in the $i$ area of Beijing-Tianjin-Hebei region during period $t$.

According to Equation (3), the contribution of carbon emission structure increment and efficiency increment in Beijing-Tianjin-Hebei region is measured, which can be expressed as:

$$
\begin{gathered}
E \alpha_{i}^{t}+E \beta_{i}^{t}=1 \\
C \alpha_{i}^{t}+C \beta_{i}^{t}=1 \\
E \alpha_{i}^{t}=\frac{\left|\Delta E_{i s}^{t}\right|}{\left|\Delta E_{i s}^{t}\right|+\left|\Delta E_{i e}^{t}\right|} \\
E \beta_{i}^{t}=\frac{\left|\Delta E_{i e}^{t}\right|}{\left|\Delta E_{i s}^{t}\right|+\left|\Delta E_{i e}^{t}\right|} \\
C \alpha_{i}^{t}=\frac{\left|\Delta C_{i s}^{t}\right|}{\left|\Delta C_{i s}^{t}\right|+\left|\Delta C_{i e}^{t}\right|} \\
C \beta_{i}^{t}=\frac{\left|\Delta E_{i e}^{t}\right|}{\left|\Delta C_{i s}^{t}\right|+\left|\Delta C_{i e}^{t}\right|}
\end{gathered}
$$

In formula (4), $C \alpha_{i}^{t}$ represents the contribution of structural increment of carbon emission in the $i$ area of Beijing-Tianjin-Hebei region, and $C \beta_{i}^{t}$ represents the contribution of the carbon emission efficiency increment in the $i$ area of BeijingTianjin-Hebei region. If the $C \alpha_{i}^{t}$ is larger than $C \beta_{i}^{t}$, it indicates that the contribution of carbon emission structure increment in the $i$ area of Beijing-Tianjin-Hebei region in period $t$ 
exceeds the contribution of efficiency increment. On the contrary, it shows that the carbon emission efficiency increment of the $i$ area in BeijingTianjin-Hebei region in period $t$ exceeds the contribution degree of the structural increment.

\subsection{Decoupling Model of Carbon Emission Evaluation}

With reference to the decoupling identification framework constructed by OECD [4], the three

Table 1. A framework for identifying the trend of carbon emission decoupling in Beijing-Tianjin-Hebei region

\begin{tabular}{|c|c|c|c|c|}
\hline \multicolumn{3}{|c|}{ change of index } & \multirow{2}{*}{$\begin{array}{c}\text { change of elastic } \\
\text { coefficient }\end{array}$} & \multirow{2}{*}{$\begin{array}{l}\text { decoupling } \\
\text { trend }\end{array}$} \\
\hline $\begin{array}{l}\text { index of driving } \\
\text { force }\end{array}$ & pressure index & efficiency index & & \\
\hline increase & decrease & enhancement & $<0$ & $\begin{array}{l}\text { strong } \\
\text { decoupling }\end{array}$ \\
\hline increase & growth & enhancement & $(0,0.8)$ & weak decoupling \\
\hline recession & decrease & enhancement & $>1.2$ & $\begin{array}{l}\text { decelerative } \\
\text { decoupling }\end{array}$ \\
\hline recession & growth & reduction & $>0$ & $\begin{array}{l}\text { strong negative } \\
\text { decoupling }\end{array}$ \\
\hline recession & decrease & reduction & $(0,0.8)$ & $\begin{array}{l}\text { weak negative } \\
\text { decoupling } \\
\text { expansive }\end{array}$ \\
\hline increase & growth & reduction & $>1.2$ & $\begin{array}{l}\text { negative } \\
\text { decoupling }\end{array}$ \\
\hline $\begin{array}{l}\text { increase } \\
\text { recession }\end{array}$ & $\begin{array}{l}\text { growth } \\
\text { decrease }\end{array}$ & 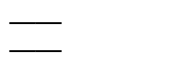 & $\begin{array}{l}(0.8,1.2) \\
(0.8,1.2)\end{array}$ & $\begin{array}{l}\text { growing link } \\
\text { decaying link }\end{array}$ \\
\hline
\end{tabular}

Note: Eight energy sources, including coal, coke, gasoline, kerosene, diesel, fuel oil, natural gas and liquefied petroleum gas, were selected to calculate the carbon emissions in

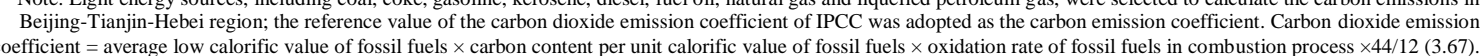
$=$ average low calorific value of fossil fuels $\times$ carbon content per unit calorific value of fossil fuels $\times$ oxidation rate of fossil fuels in combustion process $\times 44 / 12(3.67)$.
Among them, the carbon dioxide emission coefficients of natural gas and coal refer to the carbon dioxide emission coefficients of natural gas and raw coal in the oilfield respectively.

In "Table 1", the elastic coefficient of decoupling between carbon emissions and economic growth in Beijing-Tianjin-Hebei region can be expressed as follows:

$$
\left\{\begin{array}{l}
A_{i}(t)=\frac{\Delta E_{i}(t) / E_{i}(0)}{\Delta G D P_{i j}(t) / G D P_{i j}(0)}(5) \\
B_{i}(t)=\frac{\Delta C_{i}(t) / C_{i}(0)}{\Delta G D P_{i}(t) / G D P_{i}(0)}
\end{array}\right.
$$

In formula (5), $A_{i}(t)$ and $B_{i}(t)$ represent the elastic coefficients of decoupling between carbon emissions and economic growth in the $i$ area of Beijing-Tianjin-Hebei region in period $t$, respectively; $\Delta E_{i}(t)$ and $\Delta C_{i}(t)$ represent the carbon dioxide emission increment in the $i$ area in Beijing-Tianjin-Hebei region in period $t$ relative to the base period; $E_{i}(0)$ and $C_{i}(t)$ represent the carbon dioxide emissions in the $i$ area of BeijingTianjin-Hebei region in the base period respectively; $\triangle G D P_{i}(t)$ represents the increment of economic output value in the $i$ area of BeijingTianjin-Hebei region in period $t$ relative to the base period; $G D P_{i}(0)$ represents the economic types of indicators were coupled to construct the decoupling index taking the gross economic output as the driving force index, the carbon emission as the pressure index, and the energy consumption and carbon emission per 10,000 yuan of GDP as the efficiency index. According to the change of decoupling indicators, the Tapio elastic coefficient method was adopted to identify the decoupling trend of carbon emissions in Beijing-Tianjin-Hebei region (see "Table 1"). output value in the $i$ area of Beijing-Tianjin-Hebei region in the base period.

\section{EMPIRICAL STUDY}

The data in this paper are from China Energy Statistical Yearbook, Beijing Statistical Yearbook, Tianjin Statistical Yearbook and Hebei Statistical Yearbook from 1995 to 2016.

\subsection{Correlation Analysis of the Energy Consumption in the Economic industries}

\subsubsection{Correlation Characteristics of Energy Consumption at Regional and Industrial Levels}

Beijing-Tianjin-Hebei region is one of the three most dynamic growth nuclei of in Chinese economy. From 1996 to 2016, the GDP of BeijingTianjin-Hebei region increased from 595.03 billion yuan to 4.714 .18 billion yuan, with an average annual growth rate of about $10 \%$. At the same time, the problem of energy consumption in this region was prominent, showing a sustained growth. 
Among them, Beijing saw its energy consumption increased from 37.345 million tons to 69.617 million tons, with an average annual growth of about 1.53 million tons. Tianjin increased from 23.741 million tons to 84.414 million tons, with an average annual growth of about 2.7 million tons. As an industrial province, Hebei's energy consumption is about 6.5 times that of Beijing and 3.7 times that of Tianjin. Therefore, according to the evolution trend of energy consumption and economic development in Beijing-Tianjin-Hebei region, the correlation between energy consumption and economic and industrial development in BeijingTianjin-Hebei region from 1996 to 2016 was measured from two levels: regional level and industrial level.

\subsubsection{Correlation Characteristics of Energy Consumption at the Regional Level}

Taking the overall GDP of Beijing-TianjinHebei region as the reference sequence and the energy consumptions of Beijing, Tianjin and Hebei as the comparison sequence, the grey incidence analysis method was adopted to calculate the correlation between the energy consumption of Beijing, Tianjin and Hebei and the overall economic development of Beijing-Tianjin-Hebei region (see "Table 2 "). The study showed that there were significant differences in the impact of energy consumption in Beijing, Tianjin and Hebei on the economic growth of Beijing-Tianjin-Hebei region. The comprehensive correlation between energy consumption and the overall economic development of Beijing, Tianjin and Hebei is as follows: Hebei (0.809) > Tianjin $(0.628)>$ Beijing (0.581), that is, the energy consumption of Hebei has the greatest impact on the overall economic development of Beijing-Tianjin-Hebei region, followed by Tianjin and Beijing.

Table 2. The correlation between energy consumption and the overall economic development of Beijing, Tianjin and Hebei during 1996-2016

\begin{tabular}{llll}
\multicolumn{1}{c}{$\begin{array}{c}\text { correlative } \\
\text { degree }\end{array}$} & Beijing & Tianjin & Hebei \\
\hline absolute & 0.561 & 0.572 & 0.869 \\
correlative degree & 0.601 & 0.684 & 0.748 \\
relative correlative & 0.581 & 0.628 & 0.809 \\
degree & & \\
comprehensive & & & \\
correlative degree & & & \\
\hline
\end{tabular}

\subsubsection{Correlation Characteristics of Energy Consumption in Industrial Layer}

In 2016, having already stepped into the postindustrial stage, Beijing saw its tertiary industry accounting for more than $80 \%$. Tianjin was in the late stage of industrialization, with the secondary industry accounting for $42.4 \%$. Hebei was still in the middle stage of industrialization, with the secondary industry as the leading industry accounting for $47.6 \%$. From the perspective of energy consumption changes of the three industries in Beijing, Tianjin and Hebei, the energy consumption of the three industries in the region continued to rise and gradually stabilized. Among them, the energy consumption of the secondary industry accounted for the largest proportion in the overall energy consumption in Beijing-TianjinHebei region, which maintained about $80 \%$, and the change trend was similar to that of the overall energy consumption in Beijing-Tianjin-Hebei region (see "Figure 1"). 

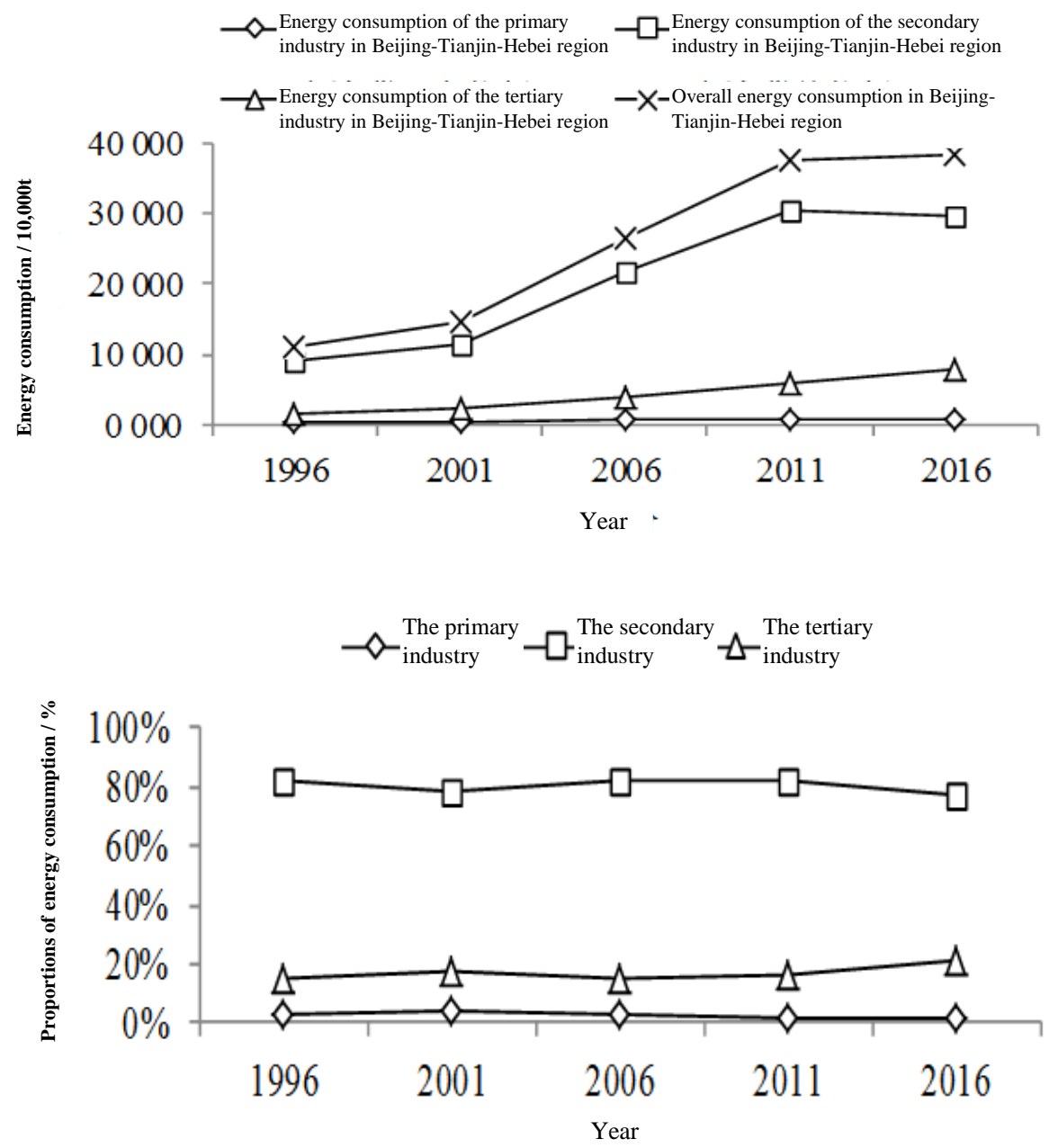

Figure 1 The overall industrial energy consumption in Beijing-Tianjin-Hebei region during 1996-2016 (up) and its industrial energy consumption ratio (below).

Taking the overall GDP of Beijing-TianjinHebei region as the reference sequence and the energy consumption of its three industries as the comparison sequence, the grey incidence analysis method was adopted to calculate the correlation between the energy consumption of the three industries of Beijing-Tianjin-Hebei and its economic development (see "Table 2"). The results showed that the comprehensive correlation between energy consumption of three industries and economic development in Beijing-Tianjin-Hebei region was as follows: energy consumption in the secondary industry $(0.815)>$ energy consumption in the tertiary industry (0.696) $>$ energy consumption in the primary industry $(0.637)$. That is, the overall energy consumption of the secondary industry in Beijing-Tianjin-Hebei region had the strongest correlation with economic development.

Table 3. The correlation between industrial energy consumption and economic development in Beijing-Tianjin-

Hebei region during 1996-2016

\begin{tabular}{llll}
\hline \multicolumn{1}{c}{$\begin{array}{c}\text { correlative } \\
\text { degree }\end{array}$} & \multicolumn{1}{c}{$\begin{array}{c}\text { the primary } \\
\text { industry }\end{array}$} & \multicolumn{1}{c}{$\begin{array}{c}\text { the secondary } \\
\text { industry }\end{array}$} & $\begin{array}{c}\text { the tertiary } \\
\text { industry }\end{array}$ \\
\hline $\begin{array}{l}\text { absolute } \\
\text { correlative degree } \\
\text { relative correlative } \\
\text { degree }\end{array}$ & 0.513 & 0.881 & 0.586 \\
$\begin{array}{l}\text { comprehensive } \\
\text { correlative degree }\end{array}$ & 0.637 & 0.750 & 0.806 \\
\hline
\end{tabular}

According to "Table 1" and "Table 2", from the regional level and the industrial level, the energy consumption in Hebei and the overall energy consumption of secondary production in BeijingTianjin-Hebei region had the greatest impact on the overall economic development of the region. It 
could be seen that the energy consumption of the secondary industry in Hebei had a significant impact on the overall economic development of Beijing-Tianjin-Hebei region. Therefore, the correlation between the energy consumption of the secondary industry in the three provinces and cities of Beijing, Tianjin and Hebei and the overall GDP of the secondary industry in the region was further calculated using the overall GDP of the secondary industry in in region as the reference sequence and the energy consumption of the secondary industry in Beijing, Tianjin and Hebei as the comparison ("Table 4"). The research showed that the comprehensive correlation degree between the

Table 4. Correlation degree between energy consumption of secondary industry and the overall development of secondary industry in Beijing-Tianjin-Hebei region from 1996 to 2016

\begin{tabular}{lccc}
\multicolumn{1}{c}{$\begin{array}{c}\text { correlative } \\
\text { degree }\end{array}$} & \multicolumn{1}{c}{ Beijing } & Tianjin & Hebei \\
\hline $\begin{array}{l}\text { absolute } \\
\text { correlative degree } \\
\text { relative correlative } \\
\text { degree }\end{array}$ & 0.575 & 0.634 & 0.741 \\
$\begin{array}{l}\text { comprehensive } \\
\text { correlative degree }\end{array}$ & 0.677 & 0.851 & 0.956 \\
\hline
\end{tabular}

\subsubsection{Correlation Characteristics of Energy Consumption in the Economic Industries in Different Planning Periods}

From the perspective of energy consumption changes in Beijing-Tianjin-Hebei region, during the "Ninth Five-year Plan" to "Twelfth Five-year Plan" period, the secondary industry is the largest energy consumer in the region, accounting for about $80 \%$ of energy consumption in the region (see "Figure $2 ")$. 

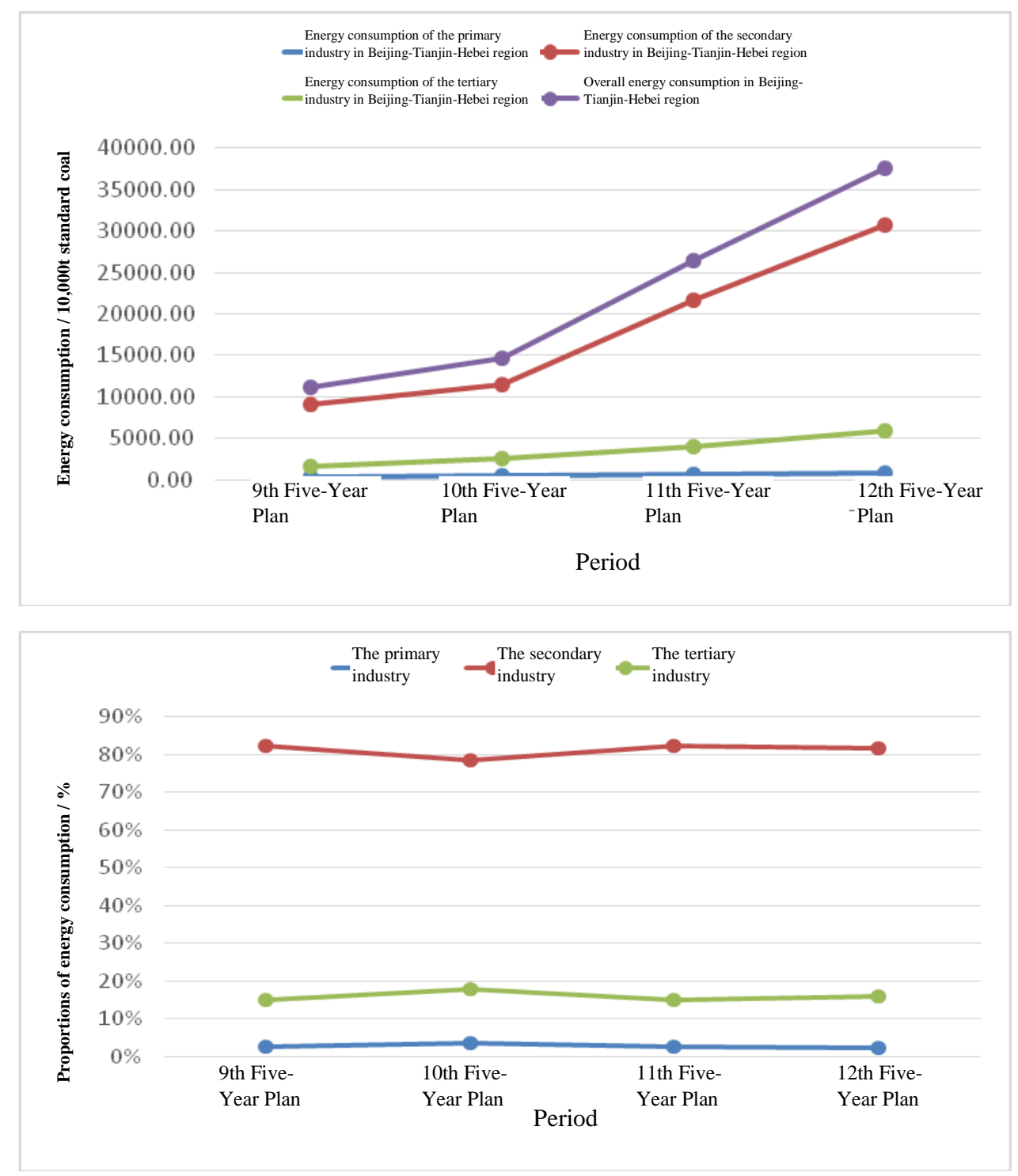

Figure 2 Energy consumption in the economic industries of Beijing-Tianjin-Hebei region from the 9th Five-Year Plan to the 12th Five-Year Plan (left) and the proportions (right).

According to Figure 1, based on the evolution trend of economic and industrial energy consumption in Beijing-Tianjin-Hebei region, the correlation degree between the economic and industrial energy consumption in Beijing-TianjinHebei region and the economic and industrial growth in Beijing-Tianjin-Hebei region during the Ninth Five-year Plan period and the Twelfth Fiveyear Plan period was measured in combination with Formula (1) (see "Table 4"). 
Table 5. The correlation between industrial energy consumption and industrial economic growth in BeijingTianjin-Hebei region in different periods

\begin{tabular}{|c|c|c|c|c|c|c|c|c|c|c|}
\hline \multirow{2}{*}{ area } & \multirow{2}{*}{ period } & \multicolumn{3}{|c|}{ the primary industry } & \multicolumn{3}{|c|}{ the secondary industry } & \multicolumn{3}{|c|}{ the tertiary industry } \\
\hline & & $\alpha_{0 i 1}$ & $\beta_{0 i 1}$ & $\gamma_{0 i 1}$ & $\alpha_{0 i 2}$ & $\beta_{0 i 2}$ & $\gamma_{0 i 2}$ & $\alpha_{0 i 3}$ & $\beta_{0 i 3}$ & $\gamma_{0 i 3}$ \\
\hline \multirow{4}{*}{ Beijing } & $\begin{array}{l}\text { the 9th Five- } \\
\text { Year Plan }\end{array}$ & 0.582 & 0.501 & 0.542 & 0.500 & 0.500 & 0.500 & 0.653 & 0.500 & 0.577 \\
\hline & $\begin{array}{l}\text { the 10th Five- } \\
\text { Year Plan }\end{array}$ & 0.523 & 0.500 & 0.512 & 0.500 & 0.500 & 0.500 & 0.638 & 0.500 & 0.569 \\
\hline & $\begin{array}{l}\text { the 11th Five- } \\
\text { Year Plan }\end{array}$ & 0.511 & 0.500 & 0.505 & 0.500 & 0.500 & 0.500 & 0.613 & 0.500 & 0.557 \\
\hline & $\begin{array}{l}\text { the 12th Five- } \\
\text { Year Plan }\end{array}$ & 0.509 & 0.500 & 0.504 & 0.500 & 0.500 & 0.500 & 0.593 & 0.500 & 0.546 \\
\hline \multirow{4}{*}{ Tianjin } & $\begin{array}{l}\text { the 9th Five- } \\
\text { Year Plan }\end{array}$ & 0.501 & 0.501 & 0.501 & 0.500 & 0.500 & 0.500 & 0.631 & 0.501 & 0.566 \\
\hline & $\begin{array}{l}\text { the 10th Five- } \\
\text { Year Plan }\end{array}$ & 0.500 & 0.500 & 0.500 & 0.562 & 0.500 & 0.531 & 0.539 & 0.500 & 0.520 \\
\hline & $\begin{array}{l}\text { the 11th Five- } \\
\text { Year Plan }\end{array}$ & 0.502 & 0.500 & 0.501 & 0.592 & 0.500 & 0.546 & 0.530 & 0.500 & 0.515 \\
\hline & $\begin{array}{l}\text { the 12th Five- } \\
\text { Year Plan }\end{array}$ & 0.514 & 0.500 & 0.507 & 0.604 & 0.500 & 0.552 & 0.530 & 0.500 & 0.515 \\
\hline \multirow{4}{*}{ Hebei } & $\begin{array}{l}\text { the 9th Five- } \\
\text { Year Plan }\end{array}$ & 0.738 & 0.510 & 0.624 & 0.792 & 0.500 & 0.646 & 0.529 & 0.500 & 0.514 \\
\hline & $\begin{array}{l}\text { the 10th Five- } \\
\text { Year Plan }\end{array}$ & 0.965 & 0.504 & 0.734 & 0.785 & 0.500 & 0.643 & 0.560 & 0.500 & 0.530 \\
\hline & $\begin{array}{l}\text { the 11th Five- } \\
\text { Year Plan }\end{array}$ & 0.889 & 0.504 & 0.696 & 0.852 & 0.500 & 0.676 & 0.573 & 0.500 & 0.537 \\
\hline & $\begin{array}{l}\text { the 12th Five- } \\
\text { Year Plan }\end{array}$ & 0.807 & 0.503 & 0.655 & 0.963 & 0.500 & 0.731 & 0.572 & 0.500 & 0.536 \\
\hline
\end{tabular}

According to "Table 5", from the perspective of the correlation between energy consumption and output value of the primary industry in BeijingTianjin-Hebei region during the Ninth Five-year Plan to the Twelfth Five-year Plan period, (1) absolute correlation changes were shown as follows: Beijing continued to decline (from 0.582 to 0.509 ), Tianjin continued to rise (from 0.501 to 0.514 ), and Hebei rose first and then fell (from 0.738 to 0.807 ). However, Hebei consumed far more energy than Tianjin and Beijing, indicating the strongest correlation between the energy consumption of Hebei's primary industry and the output value of the primary industry in BeijingTianjin-Hebei region. (2) The relative correlation degree of Beijing and Tianjin was stable at about 0.500 , while that of Hebei was slightly decreased from 0.510 to 0.503 . This indicated that there was no significant difference in the correlation between the energy consumption of the primary industry in Beijing, Tianjin and Hebei and the output value change rate of the primary industry in the region in different periods. (3) The changes in the comprehensive correlation were as follows: Beijing continued to decline (from 0.542 to 0.504 ), Tianjin was stable and increased slightly (from 0.501 to $0.507)$, and Hebei rose first and then decreased (from 0.624 to 0.655 ). In general, the energy consumption of Hebei's primary industry has the most significant correlation with the development of the primary industry in Beijing-Tianjin-Hebei region.

From the perspective of the correlation degree between the energy consumption of the secondary industry and the output value of the secondary industry in Beijing-Tianjin-Hebei region during the 9th Five-Year Plan to the 12th Five-Year Plan period, (1) the absolute correlation degree changes were as follows: Beijing stabilized (maintained at around 0.500), Tianjin increased slightly (from 0.500 to 0.604 ), and Hebei increased significantly (from 0.792 to 0.963). Hebei was far ahead of Tianjin and Beijing. It showed that the energy consumption of the secondary industry in Hebei had the strongest correlation with the output value of the secondary industry in Beijing-Tianjin-Hebei region. (2) The change of relative correlation degree was as follows: Beijing, Tianjin and Hebei were all stable at about 0.500 . This indicates that there was no significant difference in the correlation between the energy consumption of the secondary industry in Beijing, Tianjin and Hebei and the output value of the secondary industry in Beijing-Tianjin-Hebei region in different periods. (3) The changes of comprehensive correlation degree were as follows: Beijing was stable (maintained at about 0.500), Tianjin was slightly increased (from 0.500 to 0.552 ), and Hebei was 
significantly increased (from 0.646 to 0.731 ). In general, the energy consumption of the secondary industry in Hebei has the most significant correlation with the development of the secondary industry in Beijing-Tianjin-Hebei region.

From the perspective of the correlation between the energy consumption of the tertiary industry and the output value of the tertiary industry in BeijingTianjin-Hebei region during the "Ninth Five-Year" to "12th Five-Year" period, (1) the absolute correlation showed a continuous decline in Beijing (from 0.653 to 0.593 ), a decline and stabilization in Tianjin (from 0.631 to 0.530 ) and a slight increase in Hebei (from 0.529 to 0.572). Among them, Beijing surpassed Tianjin and Hebei. The correlation between energy consumption of the tertiary industry in Beijing and output value of the tertiary industry in the whole region was the strongest. (2) The change of relative correlation degree was as follows: Beijing, Tianjin and Hebei were all stable at about 0.500 . This indicated that there was no significant difference in the correlation between energy consumption of the tertiary industry in Beijing, Tianjin and Hebei and

Table 6. Structure increment and efficiency increment of carbon dioxide emission in Beijing-Tianjin-Hebei region in different periods and their contribution

\begin{tabular}{|c|c|c|c|c|c|c|c|c|}
\hline \multirow[t]{2}{*}{ area } & \multirow[t]{2}{*}{ period } & \multirow{2}{*}{$\begin{array}{l}\text { Increment } \\
\text { in } \mathrm{CO} 2 \\
\text { emissions } \\
\Delta \mathrm{C} / 10,000\end{array}$} & \multicolumn{2}{|c|}{$\begin{array}{l}\text { Structural increment } \\
\text { and its contribution }\end{array}$} & \multicolumn{2}{|c|}{$\begin{array}{l}\text { Efficiency increment } \\
\text { and its contribution }\end{array}$} & \multirow[t]{2}{*}{$\begin{array}{l}\text { Elastic } \\
\text { coefficient }\end{array}$} & \multirow[t]{2}{*}{$\begin{array}{l}\text { decoupling } \\
\text { trend }\end{array}$} \\
\hline & & & $\Delta C_{s} / 10,000 t$ & $\mathrm{Ca} / \%$ & $\Delta C_{e} / 10,000 t$ & $C \beta / \%$ & & \\
\hline \multirow{4}{*}{ 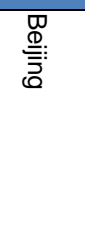 } & \multirow{4}{*}{$\begin{array}{l}\text { the 9th Five- } \\
\text { Year Plan } \\
\text { the 10th Five- } \\
\text { Year Plan } \\
\text { the 11th Five- } \\
\text { Year Plan } \\
\text { the 12th Five- } \\
\text { Year Plan }\end{array}$} & 118.16 & 6489.16 & 50.5 & -6371.01 & 49.5 & 0.01 & $\begin{array}{l}\text { weak } \\
\text { decoupling }\end{array}$ \\
\hline & & 1817.69 & 7494.93 & 57 & -5677.24 & 43 & 0.19 & $\begin{array}{l}\text { weak } \\
\text { decoupling }\end{array}$ \\
\hline & & 906.53 & 7645.22 & 53 & -6738.69 & 47 & 0.09 & $\begin{array}{l}\text { weak } \\
\text { decoupling }\end{array}$ \\
\hline & & -1521.39 & 5171.96 & 44 & -6693.35 & 56 & -0.22 & $\begin{array}{l}\text { strong } \\
\text { decoupling }\end{array}$ \\
\hline \multirow{4}{*}{ 곯: } & \multirow{4}{*}{$\begin{array}{l}\text { the 9th Five- } \\
\text { Year Plan } \\
\text { the 10th Five- } \\
\text { Year Plan } \\
\text { the 11th Five- } \\
\text { Year Plan } \\
\text { the 12th Five- } \\
\text { Year Plan }\end{array}$} & 423.11 & 3965.45 & 53 & -3542.33 & 47 & 0.08 & $\begin{array}{l}\text { weak } \\
\text { decoupling }\end{array}$ \\
\hline & & 3388.66 & 7080.10 & 66 & -3691.45 & 34 & 0.4 & $\begin{array}{l}\text { weak } \\
\text { decoupling }\end{array}$ \\
\hline & & 3816.60 & 10692.22 & 61 & -6875.62 & 39 & 0.28 & $\begin{array}{l}\text { weak } \\
\text { decoupling }\end{array}$ \\
\hline & & 1269.22 & 8771.64 & 54 & -7502.42 & 46 & 0.12 & $\begin{array}{l}\text { weak } \\
\text { decoupling }\end{array}$ \\
\hline \multirow[t]{4}{*}{$\begin{array}{l}\frac{T}{\mathbb{D}} \\
\stackrel{\mathbb{D}}{\Phi}\end{array}$} & \multirow{4}{*}{$\begin{array}{l}\text { the 9th Five- } \\
\text { Year Plan } \\
\text { the 10th Five- } \\
\text { Year Plan } \\
\text { the 11th Five- } \\
\text { Year Plan } \\
\text { the 12th Five- } \\
\text { Year Plan }\end{array}$} & 6062.11 & 15245.10 & 62 & -9182.99 & 38 & 0.34 & $\begin{array}{l}\text { weak } \\
\text { decoupling }\end{array}$ \\
\hline & & 22602.66 & 27359.91 & 85 & -4757.25 & 15 & 0.78 & $\begin{array}{l}\text { weak } \\
\text { decoupling }\end{array}$ \\
\hline & & 15691.53 & 44114.59 & 61 & -28423.06 & 39 & 0.29 & $\begin{array}{l}\text { weak } \\
\text { decoupling }\end{array}$ \\
\hline & & 6760.06 & 26621.92 & 57 & -19861.86 & 43 & 0.22 & $\begin{array}{l}\text { weak } \\
\text { decoupling }\end{array}$ \\
\hline \multirow{4}{*}{ 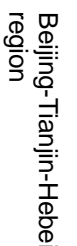 } & \multirow{4}{*}{$\begin{array}{l}\text { the 9th Five- } \\
\text { Year Plan } \\
\text { the 10th Five- } \\
\text { Year Plan } \\
\text { the 11th Five- } \\
\text { Year Plan } \\
\text { the 12th Five- } \\
\text { Year Plan }\end{array}$} & 6603.38 & 26512.50 & 57 & -19909.12 & 43 & 0.2 & $\begin{array}{l}\text { weak } \\
\text { decoupling }\end{array}$ \\
\hline & & 27809.01 & 43301.90 & 74 & -15492.89 & 26 & 0.57 & $\begin{array}{l}\text { weak } \\
\text { decoupling }\end{array}$ \\
\hline & & 20414.66 & 63042.62 & 60 & -42627.96 & 40 & 0.26 & $\begin{array}{l}\text { weak } \\
\text { decoupling }\end{array}$ \\
\hline & & 6507.89 & 44952.04 & 54 & -38444.15 & 46 & 0.12 & $\begin{array}{l}\text { weak } \\
\text { decoupling }\end{array}$ \\
\hline
\end{tabular}


According to "Table 6", with the transformation and upgrading of industrial structure in BeijingTianjin-Hebei region during the "9th Five-year Plan" to "12th Five-year Plan" period, the carbon dioxide emission increment in Beijing, Tianjin and Hebei showed an overall trend of "first rising and then falling", but the average efficiency increment and its contribution were still smaller than its structural increment and its contribution. Only in the 12th Five-Year Plan period, the carbon dioxide emission increment in Beijing is negative, and the efficiency increment and its contribution are greater than the structural increment and its contribution.
During the 9th Five-Year Plan to the 12th FiveYear Plan period, under the superimposed effect of carbon dioxide emissions from Beijing, Tianjin and Hebei, the contribution of structural increment of carbon dioxide emissions in Beijing-Tianjin-Hebei region decreased from $57 \%$ to $54 \%$, while its contribution of efficiency increase increased from $43 \%$ to $46 \%$. In general, the increase of carbon dioxide emissions in Beijing-Tianjin-Hebei region is the most sensitive to Hebei (see "Figure 3").

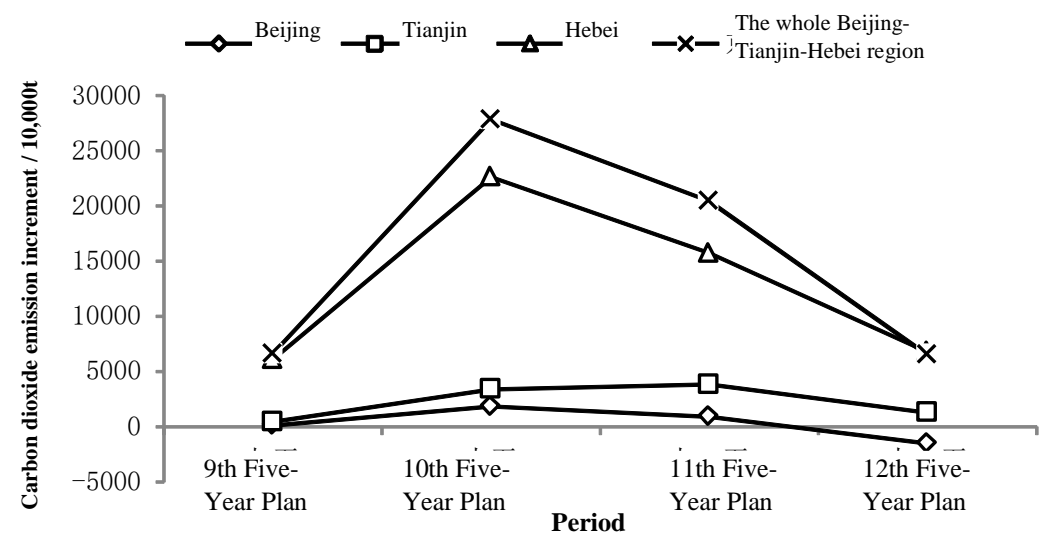

Figure 3 Change trend of carbon dioxide emission increment in Beijing-Tianjin-Hebei region in different periods.

\section{CONCLUSION}

This paper constructed and analyzed the correlation characteristics of energy consumption in the economic industries and economic growth in different periods in Beijing-Tianjin-Hebei region, measured the contribution degree of structural increment and efficiency increment of the carbon emissions, and distinguished the decoupling trend of carbon emission in Beijing-Tianjin-Hebei region. The results showed that: during the 9th Five-Year Plan period and the 12th Five-Year Plan period, the energy consumption of Hebei's primary and secondary industries has the most significant correlation with the growth of the primary and secondary industries in Beijing-Tianjin-Hebei region. The energy consumption of the tertiary industry in Beijing has the most significant correlation with the growth of the tertiary industry in Beijing-Tianjin-Hebei region. On the whole, the key path to the decoupling between carbon emissions and economic growth in Beijing-TianjinHebei region is "optimizing the industrial structure" and "improving energy consumption efficiency".
That means to realize the "zero growth" or "negative growth" of energy consumption in the secondary industry and the tertiary industry in Beijing-Tianjin-Hebei region while ensuring the "zero growth" of energy consumption in the primary industry in the region. To this end, countermeasures and suggestions from three aspects are put forward as follows:

\subsection{Further Accelerating the Agricultural Structural Transformation in Tianjin and Hebei Based on the Resource Endowment, Environmental Carrying Capacity and Agricultural Development in Beijing-Tianjin-Hebei Region}

Specific measures include: developing urban modern agriculture as the main direction, highlighting the six functions of service, ecology, quality, science and technology, income increase and inheritance, promoting the five key tasks, so as to optimize the agricultural industrial structure; vigorously developing ecological circular 
agriculture, and striving to build an ecological conservation circle around Beijing and Tianjin; constructing an innovative highland of agricultural science and technology with the emphasis on seed industry and informatization; focusing on the construction of an agriculture that serves cities, is livable and ecological, of high quality and efficiency, is innovative in science and technology, enriches farmers, and inherits agricultural civilization, so as to make agriculture present countryside landscape, serve as industrial park, be diversified in functions, develop green and ecological environment, and play a leading role in making breakthroughs.

\subsection{Accelerating the Industrial \\ Restructuring of the Secondary and Tertiary Industries In Beijing-Tianjin- Hebei Region, and Further Accelerating the Structural Transformation of the Secondary and Tertiary Industries in Hebei and Tianjin}

The measures include: vigorously transforming traditional industries and continue to promote high energy consumption industries to resolve overcapacity; actively developing new and hightech industries and reduce the proportion of high pollution and high energy consumption structures in the secondary industry, so as to promote the optimization and upgrading of industrial structures in Hebei and Tianjin from being led by industry to by service steadily.

\subsection{Intensifying Scientific and Technological Innovation in Beijing- Tianjin-Hebei Region, and Further Improving the Energy Efficiency of the Secondary and Tertiary Industries in Beijing, Tianjin and Hebei}

Specific measures include: promoting scientific and technological collaboration, building an open, unimpeded and shared platform for scientific and technological resources, and establishing a mechanism for connecting work, projects and investment; increasing spending on research and development for energy consumption control and input in scientific research personnel, accelerating the development of strategic emerging industries and high-tech industries, the construction of key laboratories and research centers at or above the provincial level, and the construction of national high-tech zones and science and technology parks. Finally, through government-industry-universityresearch cooperation and innovation, the energy consumption efficiency of the second and third industries in Beijing, Tianjin and Hebei will be improved, and the contribution of efficiency increment in Beijing, Tianjin and Hebei will be greater than the contribution of structural increment.

\section{AUTHORS' CONTRIBUTIONS}

Dan $\mathrm{Wu}$ is responsible for experimental design and writing, and Chenhui $\mathrm{Ji}$ is responsible for data analysis and manuscript writing.

\section{REFERENCES}

[1] Carter A.P. The economics of technological change [J].1966, 214: 25-31.

[2] FRIEDRICH S B, RAINER K. Wieviel umwelt raucht der mensch? mips-das mass fuer oekologisches wirtschaften [M]. Basel, Boston: Berlin, 1993.

[3] WEIZSÄCKER E U V, LOVINS A B, LOVINS L H, et al. Factor four: doubling wealth, halving resource use [M]. London: Earthscan, 1997

[4] OECD. Indicators to measure decoupling of environmental pressure from economic growth[R]. Paris: OECD, 2002.

[5] TAPIO P. Towards a theory of decoupling: Degrees of decoupling in the EU and the case of road traffic in Finland between 1970 and 2001 [J]. Journal of Transport Policy, 2005(12): 137-151.

[6] VEHMAS J, KAIVO-OJA J, LUUKKANEN $\mathrm{J}$, et al. Global trends of linking environmental stress and economic growth [J]. Turku: Finland Futures Research Centre, 2003, 6.

[7] AYRES R U, AYRES L W, WARR B, et al. Energy, power and work in the US economy, 1900 - 1998 [J]. Energy, 2003, 28(3): 219273.

[8] Kraft J, Kraft A. On the relationship between energy and GNP. The Journal of Energy and Development, 1978, 3(2): 401-403.

[9] Paul S, Bhattacharya R N. Causality between energy consumption and economic growth in 
India: A note on conflicting results [J]. Energy Economics, 2004, 26(6): 977-983.

[10] CLIMENT F, PARDO A. Decoupling factors on the energy-output linkage: The Spanish case [J]. Energy Policy, 2007, 35 (1): 522-528.

[11] VAN DER VOET E, VAN OERS L, MOLL $\mathrm{S}$, et al. Development of indicators to assess decoupling of economic development and environmental pressure in the EU-25 and AC3 countries [J]. Policy Review on Decoupling. RA Leiden, the Netherlends, 2005.

[12] Pirlogea C, Cicea C. Econometric perspective of the energy consumption and economic growth relation in European Union [J]. Renewable and Sustainable Energy Reviews, 2012, 16(8): 5718-5726.

[13] Liu Yijun, Wang Li, Niu Wenyuan. Decoupling of urban economic development and energy consumption in China [J]. Chinese Journal of Population Resources and Environment, 2011, 21(01): 70-77. (in Chinese)

[14] Peng Jiawen, Huang Xianjin, Zhong Taiyang, et al. Decoupling of China's Economic Growth and Energy Carbon Emissions [J]. Resources Science, 2011, 33(04): 626-633. (in Chinese)

[15] Sun Yaohua, Li Zhongmin. Analysing on the Decoupling Relationship Between Carbon Dioxide Emissions and Economic Growth in Each Province of China [J]. Chinese Journal of Population Resources and Environment, 2011, 21(05): 87-92. (in Chinese)

[16] Gai Mei, Cao Guiyan, Tian Chengshi, et al. Decoupling Analysis of Energy Carbon Emissions and Regional Economic Growth in Liaoning Coastal Economic Belt [J]. Resources Science, 2014, 41(6): 1267-1277. (in Chinese)

[17] Hu Yuan, Liu Guichun, Hu Wei. Relationship and Evolution Mechanism of Energy Carbon Emission and GDP in China - Practical Research Based on Decoupling and Serforganization Theory [J]. Resources Development and Market, 2015, 31(11): 13581362. (in Chinese)

[18] Yang J, Zhang W, Zhang Z. Impacts of urbanization on renewable energy consumption in China [J]. Journal of Cleaner Production, 2016, 114: 443-451.
[19] Zhang Kuanqi, Yan Bin, Shen Qianling. The Relationship Between Energy Consumption and Economic Growth in Beijing Based on Expanded Production Function: from the Toda-Yamomoto Causality Test and Decoupling Perspective [J]. Systems Engineering, 2017(9): 79-86. (in Chinese)

[20] Hong Siyang, Wang Hongrui, Lai Wenli, et al. Spatial Analysis and Coordinated Development Decoupling Analysis of Energyconsumption Water in China [J]. Journal of Natural Resources, 2017, 34 (5): 800-813. (in Chinese)

[21] Li A, Zhang A, Zhou Y, et al. Decomposition analysis of factors affecting carbon dioxide emissions across provinces in China[J]. Journal of Cleaner Production, 2017, 141: 1428-1444.

[22] Zhou X, Zhang M, Zhou M, et al. A comparative study on decoupling relationship and influence factors between China's regional economic development and industrial energyrelated carbon emissions [J]. Journal of Cleaner Production, 2017, 142: 783-800.

[23] Fan J L, Zhang Y J, Wang B. The impact of urbanization on residential energy consumption in China: An aggregated and disaggregated analysis [J]. Renewable and Sustainable Energy Reviews, 2017, 75: 220233.

[24] He Ze, Yang Yu, Song Zhouying, et al. The mutual evolution and driving factors of China's energy consumption and economic growth [J]. Geographical Research, 2018, 37(8): 1528-1540. (in Chinese)

[25] Yue Li, Song Yaqiong, Jiang Lingfeng. National energy efficiency of countries in the "Belt and Road" region and its decoupling from economic growth [J]. Resources Science, 2019, 31(5): 834-846. (in Chinese)

[26] [26] Wang Huanfang, $\mathrm{Hu}$ Zhenhua. The Measurement Research on the decouping Relationship Between Manufacturing Sector Economic Growth and Carbon Dioxide in China [J]. Studies in Science of Science, 2012, 30(11): 1671-1675. (in Chinese)

[27] Yang Liangjie, Wu Wei, Su Qin, Du Zhipeng, Jiang Xiaowei, et al. Carbon Emissions of Transportation Energy Consumption and Its 
Decoupling Analysis in Jiangsu Province [J]. Resources and Environment in the Yangtze Basin, 2014, 23(10): 1383-1390. (in Chinese)

[28] Guofu Zhou, Lili Gong. Factor Analysis of Carbon Footprint of Beijing Tianjin Hebei Province and Energy Consumption and Influence [J]. Economic Issues, 2014(08): 2731. (in Chinese)

[29] He Yin, Cai Mantang. Decoupling Relationship between Economic Growth and Resource Environment in Beijing-TianjinHebei Region [J]. Journal of Beijing Institute of Technology (Social Sciences Edition), 2016, 18(05): 33-41. (in Chinese)

[30] Chen Huan, Zhu Qingyuan, Xin Lu, et al. A Study on the Relationship Between Economic Growth and Energy Carbon Emissions in Beijing-Tianjin-Hebei Region: Based on the Application of Decoupling Theory [J]. Price:Theory \& Practice, 2016(12): 180-183. (in Chinese)

[31] Cheng Haisen, Ma Jing, Fan Xinye, et al. Research on the Relationship Between Energy Consumption, Economic Growth and Carbon Emission in Beijing-Tianjin-Hebei [J]. Modern Management Science, 2017(11): 8183. (in Chinese)

[32] Wang Zhongyu. An empirical study on the Relationship Between Energy Consumption, Carbon Emission and Economic Growth in Beijing-Tianjin-Hebei Region [J]. Industrial Technology Economics, 2017, 36(01): 82-92. (in Chinese)

[33] Wang Fengting, Fang Kai, Yu Chang. Decoupling Between Industrial Energy-related Carbon Emissions and Economic Growth and Its Driving Factors in Beijing, Tianjin and Hebei Urban Agglomeration - Empirical Study Based on Tapio Decoupling and LMDI Model [J]. Journal of Industrial Technological Economics, 2019, (8): 32-40. (in Chinese)

[34] Liu Sifeng, Xie Naiming. The Parallel and Uniform Properties of Several Relational Models [J]. Systems Engineering, 2007(08):98-103. (in Chinese) 